\title{
Caracterização florística e estrutural das florestas naturalmente fragmentadas no Parque Estadual do Guartelá, município de Tibagi, estado do Paraná
}

\author{
Marta Regina Barrotto do Carmo ${ }^{1,3}$ e Marco Antonio de Assis ${ }^{2}$
}

Recebido em 10/11/2010. Aceito em 17/01/2012

\section{RESUMO}

(Caracterização Florística e Estrutural das Florestas Naturalmente Fragmentadas no Parque Estadual do Guartelá, município de Tibagi, estado do Paraná) A Floresta Ombrófila Mista na região dos Campos Gerais do Paraná é naturalmente fragmentada, ocorrendo em forma de capões ou ao longo dos cursos d'água. Com o objetivo de caracterizar a composição e estrutura destes fragmentos e avaliar as correlações entre a distribuição das espécies e variáveis do solo de tal região, realizou-se um estudo no Parque Estadual do Guartelá, Município de Tibagi (24³9’10”S e $\left.50^{\circ} 15^{\prime} 25^{\prime \prime} \mathrm{W}\right)$. Foram alocadas 50 parcelas de 10x10m, distribuídas em capões de diferentes tamanhos e ao longo da floresta que acompanha o Rio Iapó, amostrando todos os indivíduos com altura $\geq 3 \mathrm{~m}$. Foram encontrados um alto número de espécies (140) e uma elevada diversidade $\left(\mathrm{H}^{\prime}=4,10\right)$, valores acima daqueles relatados para o domínio da Floresta Ombrófila Mista. As análises da composição e estrutura revelaram uma flora de transição entre a Floresta Ombrófila Mista e a Floresta Estacional Semidecidual, com uma maior similaridade com esta última, possivelmente influenciada pelo clima. Uma análise de correspondência canônica identificou as variáveis textura e acidez como as correlacionadas com a distribuição de abundâncias das espécies, ordenando dois grupos distintos: um formado pelas parcelas distribuídas nos capões, relacionadas fortemente à textura do solo; e outro pelas parcelas alocadas na floresta de galeria, associadas principalmente com a disponibilidade de nutrientes.

Palavras-chave: análise de correspondência canônica, Campos Gerais do Paraná, comunidade arbórea, fitossociologia, Floresta Ombrófila Mista

\begin{abstract}
(Structural and floral characterization of the naturally fragmented forests in the Parque Estadual do Guartelá, Tibagy municipality, Paraná, Brazil) The Araucaria forest in the region of Campos Gerais in Paraná is naturally fragmented, and is found in patches (capões) or along watercourses. The goal of this study was to characterize the structure of these fragments and to evaluate correlations between species distribution and soil variables in Parque Estadual do Guartelá, in the Tibagy municipality $\left(24^{\circ} 39^{\prime} 10^{\prime \prime} \mathrm{S}, 50^{\circ} 15^{\prime} 25^{\prime \prime} \mathrm{W}\right)$. Fifty $10 \times 10 \mathrm{~m}$ plots were allocated, which were distributed in capões of different sizes and in the forest that follow the Iapó River, and all individuals were sampled that were $\geq 3 \mathrm{~m}$ tall. A high number of species $(140)$ and diversity $\left(H^{\prime}=4.17\right)$ values were found; much higher than those related to Mixed Ombrophylous Forest. The evaluation of the composition and structure revealed a flora of transition between the Mixed Ombrophylous Forest and Semideciduous Seasonal Forest, with a greater similarity with the latter, something that is possibly influenced by the climate. A canonical correspondence analysis (CCA) identified various textures and acidity related to the distribution of abundance of the species, and revealed two distinct groups: one shaped by the plots distributed in the patches (capões), which was strongly related to the texture of the soil; and the other by the plots allocated in the gallery forest, which was associated mainly with nutrient availability.
\end{abstract}

Key words: "Campos Gerais do Paraná", canonical correspondence analysis, Mixed Ombrophylous Forest, tree community

\footnotetext{
1 Universidade Estadual de Ponta Grossa, Departamento de Biologia Geral, Ponta Grossa, PR, Brasil

2 Universidade Estadual Paulista, Departamento de Botânica, Rio Claro,SP, Brasil

3 Autor para correspondência: mrcarmo@uepg.br
} 


\section{Introdução}

A Floresta Ombrófila Mista, cujo elemento característico é a Araucaria angustifolia, distribui-se atualmente no Brasil meridional e na província de Missiones na Argentina, ocorrendo nas porções mais elevadas do planalto brasileiro principalmente nos estados do Paraná, Santa Catarina e Rio Grande do Sul, entre 500 e 1.200 metros de altitude, além de áreas disjuntas em São Paulo e Minas Gerais (Veloso et al. 1991). Este tipo de vegetação encontra-se em diferentes estágios sucessionais, nos quais as espécies mais importantes de cada associação são substituídas, propiciando a formação de sub-bosques de composição heterogênea (Klein 1960).

Em toda a extensão de ocupação, ao longo do planalto Sul Brasileiro, a floresta com araucária é interrompida pelos campos, com os quais estabelece ecótonos que representam a linha de frente da ocupação pela floresta. No estado do Paraná, onde se concentra a maior área de tal formação, distribuem-se no primeiro, segundo e a parte leste do terceiro planalto, formando ecótonos também com a Floresta Ombrófila Densa, a Savana e a Floresta Estacional Semidecidual (Klein 1960, Castelha \& Britez 2004).

No segundo planalto paranaense, e em particular na região dos Campos Gerais, a Floresta Ombrófila Mista não é bem desenvolvida devido às condições edáficas, assim os elementos florestais se apresentam com freqüência, como manchas quase circulares denominados capões ou como matas de galeria que ocorrem especialmente em encostas, diques de diabásio, pequenas depressões ou nas cabeceiras das nascentes, onde o solo é mais profundo com maior acúmulo de detritos orgânicos (Klein \& Hatschbach 1971).

Segundo Rocha \& Weirich Neto (2007), na fitofisionomia atual de tal região, estas áreas florestais são na maioria secundárias, em consequência de explorações, tanto no ciclo da erva-mate quanto no da madeira. No entanto, com avanço tecnológico e o fim da extração de material lenhoso, a vegetação começou naturalmente a se regenerar. Assim, as áreas mais representativas estão em processo de regeneração, tendo já alcançado, em função do solo e clima, um estágio de equilíbrio secundário (Castella \& Britez 2004).

Apesar da importância na paisagem paranaense, trabalhos sobre a estrutura destas florestas são incipientes e estão concentrados principalmente no primeiro planalto (Oliveira \& Rotta 1982, Silva \& Marconi 1990). Na região dos Campos Gerais, os levantamentos fitossociológicos foram realizados por Galvão et al. (1989); Silva et al. (1992); Nakajima et al. (1996); Dias et al. (1998). Estes estudos mostram diferenças estruturais significativas entre as áreas, sugerindo que variáveis ambientais estariam determinando a preferência de habitats pelas diferentes populações que constituem as fitocenoses.

Com o objetivo de entender a estrutura e distribuição das fisionomias florestais da região dos Campos Gerais, realizou-se um levantamento fitossociológico das áreas de floresta naturalmente fragmentadas do Parque Estadual do
Guartelá, Município de Tibagi. Nesta unidade de conservação, os fragmentos de Floresta Ombrófila Mista ocupam posições distintas, ao longo do canyon do rio Iapó e em topo de encosta, estabelecendo contatos com o campo e cerrado. Também sofrem forte influência da Floresta Estacional Semidecidual (Castelha \& Britez 2004) pela posição geográfica (mais ao norte).

Este estudo procurou responder as seguintes questões: a) Estas florestas fragmentadas naturalmente implicam em maior riqueza e diversidade de espécies quando comparadas com áreas contínuas de Floresta Ombrófila Mista? b) A composição florística caracteriza uma área ecotonal entre as formações Floresta Ombrófila Mista e Floresta Estacional Semidecidual? c) Há uma correlação entre a distribuição das abundâncias das espécies e as variáveis do solo nas áreas de capão e floresta de galeria?

Pela característica de distribuição em mosaico da fisionomia florestal do Parque Estadual do Guartelá, espera-se encontrar uma alta variação na estrutura e composição, decorrentes das diferentes condições edáficas, da confluência exercida pelos fatores climáticos, pelo contato com as formações vegetais adjacentes e, ainda, pela influência da Floresta Estacional Semidecidual, o que acarretaria em maior diversidade quando comparada com áreas de florestas contínuas.

\section{Material e métodos}

\section{Caracterização da área de estudo}

O estudo foi realizado no Parque Estadual do Guartelá (PEG), localizado no Município de Tibagi, no Segundo Planalto do estado do Paraná (Fig. 1), nas coordenadas $24^{\circ} 39^{\prime} 10^{\prime}$ 'S e $50^{\circ} 15^{\prime} 25^{\prime \prime} \mathrm{W}$, totalizando uma área de 789,97 hectares. O PEG é uma das importantes Unidades de Conservação da região dos Campos Gerais, estando inserido na Área de Preservação Ambiental (APA) da Escarpa Devoniana.

Segundo a classificação de Koeppen, apresenta clima do tipo Cfa (subtropical úmido quente), com influência indireta do clima $\mathrm{Cfb}$ (temperado sempre úmido). Por estar inserido na escarpa Devoniana, o PEG encontra-se sob influência de um relevo com topografia muito diversificada, variando de suave-ondulado a extremamente acidentado, com as escarpas chegando a mais de $100 \mathrm{~m}$ de altura. Dentro do parque encontra-se a porção central do canyon do rio Iapó (também chamado de Guartelá). O referido rio provém do Primeiro Planalto paranaense e rompe a escarpa em profunda e longa garganta para atingir o Segundo Planalto, num percurso de $30 \mathrm{~km}$, entre os Municípios de Castro e Tibagi, com desnível máximo de $450 \mathrm{~m}$ em relação ao topo da escarpa (Melo 2000). Na área do PEG a altitude ao longo do Rio Iapó varia entre 800 e $900 \mathrm{~m}$ cujos pontos mais elevados estão entre 1050 e $1150 \mathrm{~m}$. 


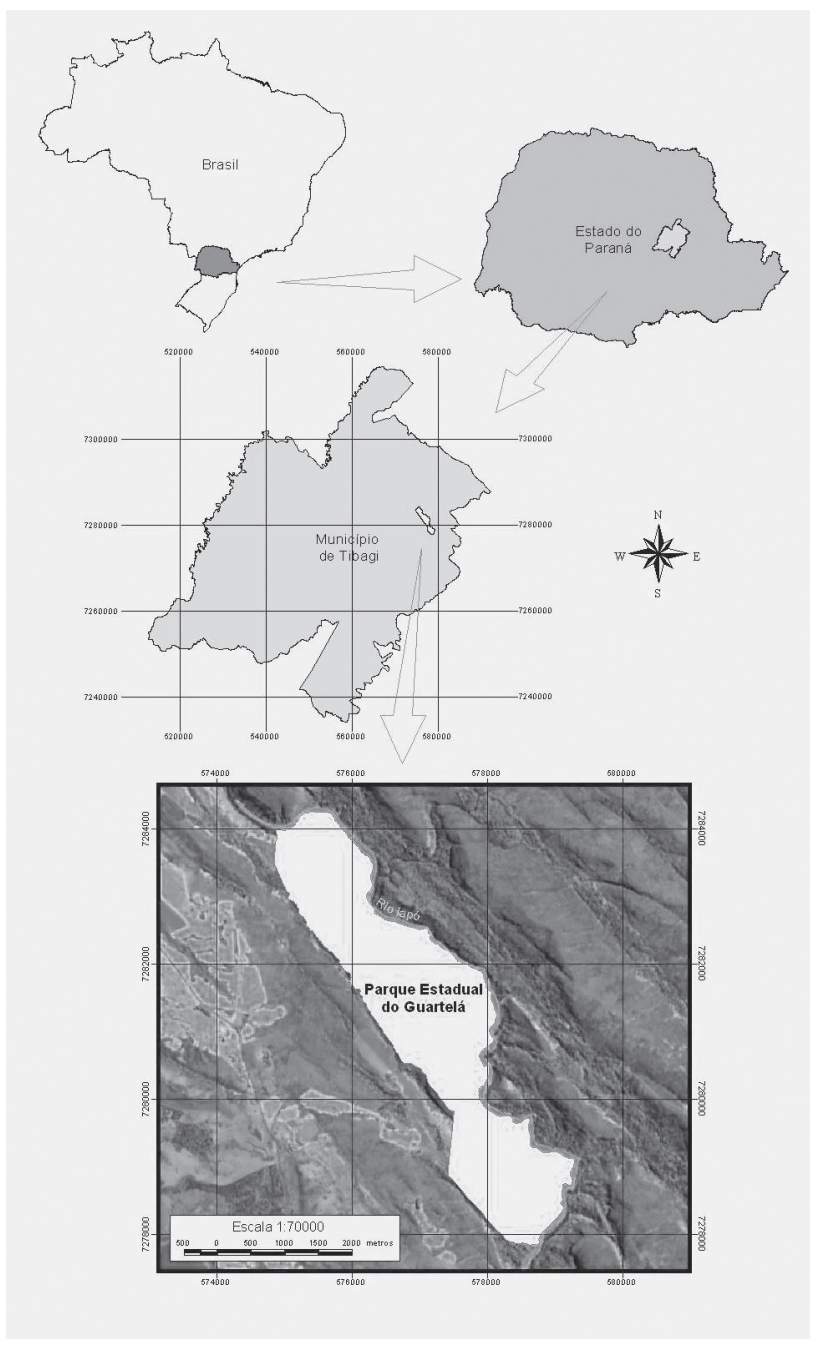

Figura 1. Localização do Parque Estadual do Guartelá no estado do Paraná, Brasil

O PEG é caracterizado por um mosaico de diferentes tipos vegetacionais que são classificados, segundo Veloso et al. (1991), por: Estepe Gramíneo-lenhosa, Savana Arborizada e Floresta Ombrófila Mista. A área florestal ocupa posições distintas, localizando-se geralmente nas encostas, nos vales, acompanhando o rio Iapó ou em formações denominados capões de várias dimensões e extensões, ora retilíneas encaixadas em fundo de vales, ora em formas arredondadas.

\section{Coleta e Análise de Dados}

\section{Composição e estrutura}

Foram estabelecidas parcelas de 10x10m, alocadas em pares e distribuídas aleatoriamente da seguinte maneira (Fig. 2): 30 parcelas em sete capões de diferentes tamanhos, variando de duas parcelas em áreas de dimensões muito restritas a seis parcelas em capões maiores; e mais 20 parcelas, em quatro localidades na floresta de galeria do rio
Iapó, totalizando uma área amostral de 0,5 ha. Incluíram-se na amostragem os indivíduos arbóreos e arbustivos que apresentavam altura igual ou superior a $3 \mathrm{~m}$.

A demarcação dos indivíduos foi realizada por meio de plaquetas numeradas. As anotações a respeito dos espécimes constavam do número do indivíduo, o valor da altura (estimado para as árvores) e o valor da circunferência à altura do peito (CAP).

A partir dos dados tomados em campo foram calculados, por meio do programa Fitopac (Shepherd 1995), o índice de diversidade de Shannon ( $\left.\mathrm{H}^{\prime}\right)$, a eqüabilidade (J) e os descritores fitossociológicos: densidade relativa, freqüência relativa, dominância relativa e valor de importância, de acordo com Mueller-Dombois \& Ellenberg (1974). Para possibilitar comparações com outros estudos, foram calculados estes mesmos parâmetros selecionando os indivíduos amostrados com diâmetro à altura do peito (DAP) maior ou igual a $5 \mathrm{~cm}$. Foi elaborada a curva espécie-área (Mueller-Dombois \& Ellenberg 1974) para testar a suficiência amostral das áreas incluídas no estudo.

\section{Comparações florísticas}

Para avaliar a influência da composição de espécies arbóreas e arbustivas das áreas florestais do PEG em relação às floras das formações Ombrófila Mista e Estacional Semidecidual, foi montada uma matriz de presença/ausência dos taxa identificados em nível específico encontrados na bibliografia disponível de 28 levantamentos realizados nestas formações no estado do Paraná. Com base nesta matriz, que constou de 447 espécies revisadas e sinonimizadas, realizou-se a análise de agrupamento (UPGMA) usando o índice de Jaccard como medida de semelhança. Para os cálculos e a apresentação do dendrograma utilizou-se o programa PC-Ord for Windows versão 4.14 (McCune \& Mefford 1999).

\section{Obtenção dos dados de solo}

Com auxílio de um trado foram obtidas amostras de solos das 50 parcelas estabelecidas. As coletas eram realizadas em cinco pontos dentro dos quadrados de 10x10m (nas quatro vertentes e no centro), a uma profundidade de 0-20 cm. No entanto, em algumas parcelas (P17, P18, P33, P34, P37, P38) foram realizadas coletas de solo superficial, pois estavam alocadas em ambientes com predominância de rocha exposta.

Todas as amostras foram encaminhadas para os Laboratórios de Fertilidade e Física do Solo do Setor de Ciências Agrárias da Universidade Estadual de Ponta Grossa (PR), onde procederam as análises químicas e granulométricas.

\section{Correlações entre distribuição de espécies e variáveis do solo}

As relações entre as propriedades químicas, textura dos solos e distribuição das espécies nas parcelas foram avaliadas por meio de uma análise de correspondência canônica-CCA (ter Braak 1987), utilizando-se o Programa PC-ORD for Windows versão 4.14 (McCune \& Mefford 1999). 


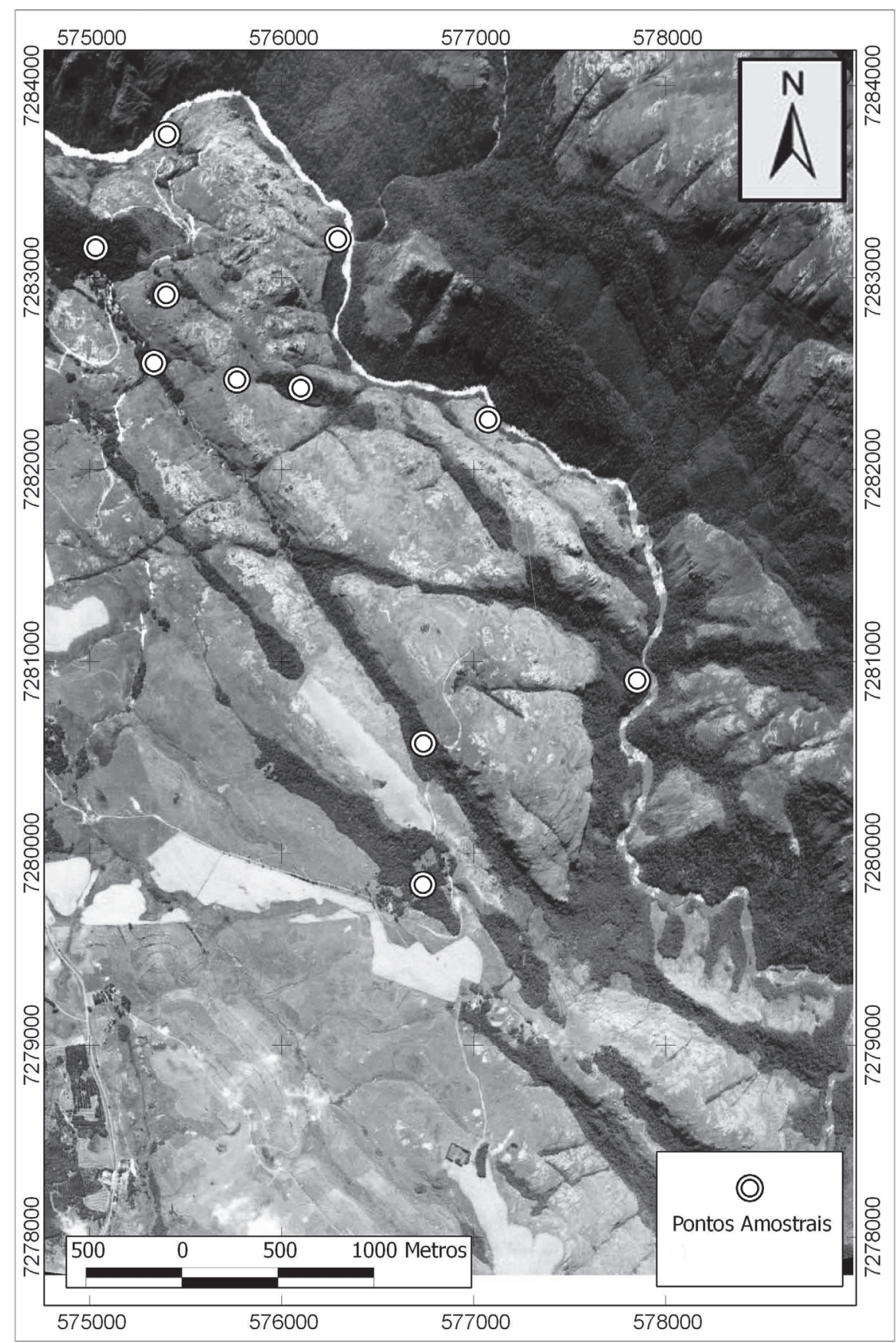

Figura 2. Localização das áreas amostrais de vegetação florestal no Parque Estadual do Guartelá, Tibagi, PR.

Nessa análise os dados de número de indivíduos por espécie em cada parcela foram relacionados aos seguintes parâmetros: teores de areia, silte e argila $\left(\mathrm{g} \mathrm{Kg}^{-1}\right) ; \mathrm{pH}$ em $\mathrm{CaCl}_{2}$; níveis de $\mathrm{P}$ (mg/dm 3 ), C-org (g/dm), K, Ca, Mg e $\mathrm{Al}(\mathrm{cmolc} / \mathrm{dm} 3)$; saturação por bases $(\mathrm{V})$ e saturação por $\mathrm{Al}(\mathrm{m})$. As variáveis do solo (vs.) expressas em porcentagem (argila, silte, areia, $\mathrm{V}$ e $\mathrm{m}$ ) foram transformadas pela expressão arco-seno (vs. 0,01 ), visando diminuir os desvios de suas distribuições em relação à distribuição normal (Zar 1996). A matriz de abundância das espécies foi constituída pelo número de indivíduos por parcela das
45 espécies que apresentavam dez ou mais indivíduos na amostra total.

Com o objetivo de excluir variáveis pouco correlacionadas com os eixos da ordenação $(r<0,4)$ e as redundantes $(r>0,8)$, foram processadas análises preliminares com todas as $12 \mathrm{va}-$ riáveis. A CCA final foi processada com as seis variáveis mais fortemente correlacionadas com os eixos de ordenação: teores de areia e argila e níveis de $\mathrm{Mg}, \mathrm{P}$, $\mathrm{Al}$ e $\mathrm{m}$ (saturação por $\mathrm{Al}$ ). Apesar de redundantes, as variáveis $\mathrm{Al}$ e $\mathrm{m}$ foram mantidas na análise, pois a primeira teve maior correlação com o eixo 1 , enquanto a segunda apresentou alta correlação com o eixo 2. 
Foi aplicado o teste de permutação de Monte Carlo (500 permutações) para verificar a significância das correlações entre os padrões emergentes das espécies e as variáveis edáficas na CCA final.

\section{Resultados}

\section{Estrutura}

Foram encontradas 43 famílias, 85 gêneros, totalizando 140 espécies, sendo que destas, quatro permanecem sem identificação (Tab. 1). A densidade total foi de 3866 indivíduos por ha, enquanto a área basal foi de 44,97 por ha. A diversidade calculada através do índice de Shannon foi de 4,10 e a equabilidade de 0,83 . Ao selecionar da amostra os indivíduos com DAP $\geq 5 \mathrm{~cm}$, os valores de diversidade e equabilidade encontrados foram, respectivamente, 4,06 e 0,84, sendo que número total de espécies foi de 124 . Observou a tendência à estabilização da curva espécie-área na amostra (Fig. 3), podendo-se sugerir que houve suficiência amostral.

As famílias com maior riqueza em espécies foram: Myrtaceae (21 espécies), Lauraceae (15), Euphorbiaceae (12), Fabaceae (12) e Rubiaceae (7). Apenas estas cinco famílias constituíram 47,9\% do total de espécies amostradas.

Estas mesmas famílias juntamente com Celastraceae, Vochysiaceae, Rutaceae, Salicaceae e Myrsinaceae apresentam os maiores valores de importância (VI), representando $73,9 \%$ da amostra.

Myrtaceae foi a família mais importante (VI= $16,5 \%)$, obtendo os maiores valores de freqüência $(F R=9,40 \%)$ e densidade $(D R=28,8 \%)$, sendo discrepante este último índice em relação às demais famílias amostradas. No entanto, obteve o $3^{\circ}$ lugar em DoR $(11,4 \%)$, devido ao pequeno porte dos indivíduos, ocupando principalmente o sub-bosque das áreas florestadas. Fabaceae foi a segunda família mais importante, alcançando o maior valor em DoR $(24,2 \%)$, devido principalmente à alta dominância dos indivíduos de Anadenanthera colubrina, Copaifera langsdorffii e Inga vera.

A análise fitossociológica (Tab. 1) revelou as espécies Maytenus robusta, Callisthene major, Anadenanthera colubrina, Copaifera langsdorffi, Calyptranthes concinna, Pera glabrata, Pilocarpus pauciflorus, Calycoretes psidiiflorus, Myrcia rostrata e Rapanea umbellata com os maiores valores de importância (VI) encontrados nas florestas do PEG, respectivamente. Estas dez espécies somam 730 indivíduos, o que representa $35 \%$ do total amostrado.

Algumas espécies se destacaram em valores de dominância, já que possuem representantes de grande porte como Anadenanthera colubrina, Callisthene major, Copaifera langsdorffi, Maytenus robusta e Pera glabrata, além de Inga vera que obteve alto valor de área basal em conseqüência das ramificações de seus caules.

Por outro lado, Pilocarpus pauciflorus, Myrcia rostrata, Calycoretes psidiiflorus, Calyptranthes concinna e Myrcia breviramis são espécies importantes do sub-bosque que alcançaram altos valores de densidade, mas pouca expressividade em relação à área basal.

Notou-se que, de um modo geral, a freqüência relativa (FR) foi o parâmetro que apresentou valores com distribuição mais uniforme entre as espécies amostradas, contudo, destacaram-se Maytenus robusta, Calyptranthes concinna e Rapanea umbellata pela ampla ocorrência, estando presentes em aproximadamente $60 \%$ das unidades amostrais.

O pinheiro-do-paraná, Araucaria angustifolia, espécie predominante da Floresta Ombrófila Mista, foi amostrado em apenas seis parcelas, representando uma densidade absoluta de 16 ind./ha. Para Aspidosperma polyneuron,

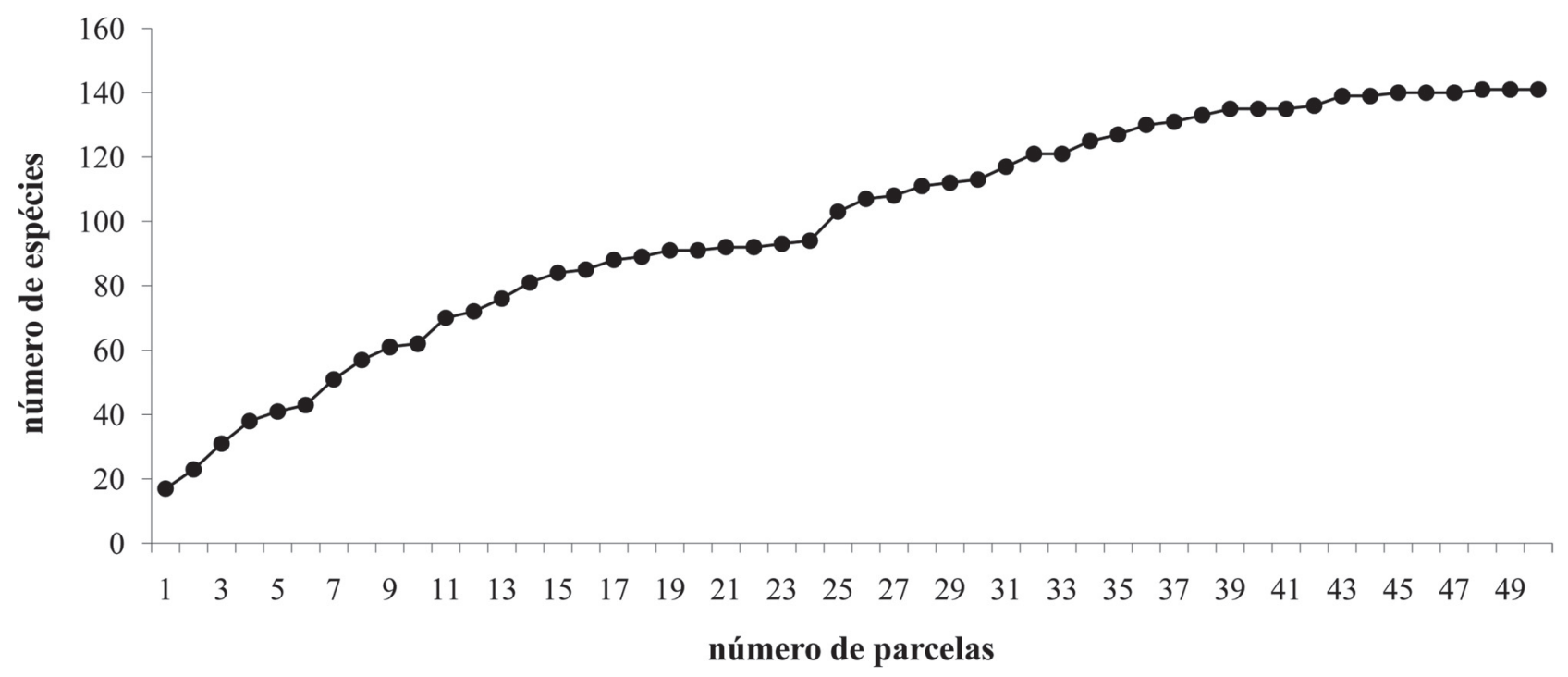

Figura 3. Curva espécie-área das amostras de vegetação florestal no Parque Estadual do Guartelá, Tibagi, PR. 
Tabela 1. Espécies arbóreas amostradas nas florestas do Parque Estadual do Guartelá, Tibagi-PR, e seus parâmetros fitossociológicos: NI-nº de indivíduos; NA-nº de parcelas; DR-densidade relativa (\%); DoR-dominância relativa (\%); FR-frequência relativa (\%); IVI-índice de valor de importância.

\begin{tabular}{|c|c|c|c|c|c|c|c|c|}
\hline Famílias & Espécies & Cód. & NI & NA & DR & DoR & FR & IVI \\
\hline Celastraceae & Maytenus robusta Reissek & Mayt ro & 103 & 30 & 5,33 & 5,30 & 3,73 & 14,36 \\
\hline Vochysiaceae & Callisthene major Mart. & Call ma & 51 & 19 & 2,64 & 8,32 & 2,36 & 13,32 \\
\hline Fabaceae & Anadenanthera colubrina (Vell.) Brenan & Anad co & 36 & 20 & 1,86 & 8,42 & 2,49 & 12,77 \\
\hline Fabaceae & Copaifera langsdorffii Desf. & Copala & 57 & 18 & 2,95 & 6,44 & 2,24 & 11,63 \\
\hline Myrtaceae & Calyptranthes concinna DC. & Caly co & 78 & 29 & 4,04 & 2,04 & 3,61 & 9,68 \\
\hline Euphorbiaceae & Pera glabrata (Schott) Baill. & Peragl & 43 & 20 & 2,22 & 4,95 & 2,49 & 9,66 \\
\hline Rutaceae & Pilocarpus pauciflorus A. St-Hil. & Pilo pa & 116 & 14 & 6,00 & 1,40 & 1,74 & 9,15 \\
\hline Myrtaceae & Calycoretes psidiiflorus (Berg.) Sobral & Caly os & 91 & 15 & 4,71 & 1,68 & 1,87 & 8,25 \\
\hline Myrtaceae & Myrcia rostrata DC. & Myrc ro & 95 & 19 & 4,91 & 0,86 & 2,36 & 8,13 \\
\hline Myrsinaceae & Rapanea umbellata Mart. & Rapa um & 60 & 28 & 3,10 & 1,49 & 3,48 & 8,07 \\
\hline Myrtaceae & Myrcia breviramis (O. Berg.) D. Legrand & Myrc br & 69 & 18 & 3,57 & 2,13 & 2,24 & 7,93 \\
\hline Salicaceae & Casearia sylvestris Sw. & Case sy & 61 & 24 & 3,16 & 1,66 & 2,99 & 7,80 \\
\hline Fabaceae & Inga vera (DC.) T. D. Penn & Inga ve & 46 & 10 & 2,38 & 4,14 & 1,24 & 7,77 \\
\hline Monimiaceae & Mollinedia clavigera Tul. & Moll cl & 57 & 24 & 2,95 & 1,26 & 2,99 & 7,20 \\
\hline Myrtaceae & Myrcia multiflora (Lam.) DC. & Myrc um & 47 & 21 & 2,43 & 1,37 & 2,61 & 6,42 \\
\hline Euphorbiaceae & Alchornea triplinervia (Spreng.) Müll. Arg. & Alch tr & 20 & 14 & 1,03 & 3,07 & 1,74 & 5,84 \\
\hline Rubiaceae & Rudgea sp. & Rudgsp & 59 & 13 & 3,05 & 0,44 & 1,62 & 5,11 \\
\hline Moraceae & Sorocea bonplandii (Baill.) Bürger, Lanj. \& Bôer & Soro bo & 43 & 17 & 2,22 & 0,37 & 2,11 & 4,71 \\
\hline Euphorbiaceae & Sebastiania schottiana Müll. Arg. & Sebasc & 28 & 11 & 1,45 & 1,76 & 1,37 & 4,58 \\
\hline Rubiaceae & Coussarea sp. & Cous sp & 42 & 9 & 2,17 & 0,76 & 1,12 & 4,05 \\
\hline Rutaceae & Esenbeckia grandiflora Mart. & Esen $g r$ & 37 & 8 & 1,91 & 1,01 & 1,00 & 3,92 \\
\hline Proteaceae & Roupala brasiliensis Klotzsch & Roup Br & 30 & 15 & 1,55 & 0,44 & 1,87 & 3,86 \\
\hline Melastomataceae & Miconia sp. & Mico sp & 12 & 10 & 0,62 & 1,95 & 1,24 & 3,81 \\
\hline Fabaceae & Leucochloron incuriale (Vell.) Barn. \& J.W. Grimes & Leuc in & 18 & 10 & 0,93 & 1,58 & 1,24 & 3,75 \\
\hline Lauraceae & Ocotea bicolor Vattimo-Gil & Ocot bi & 12 & 9 & 0,62 & 1,97 & 1,12 & 3,71 \\
\hline Salicaceae & Casearia obliqua Spreng. & Case ob & 13 & 10 & 0,67 & 1,65 & 1,24 & 3,57 \\
\hline Myrtaceae & Myrciaria cuspidata O. Berg. & Myrc cu & 35 & 10 & 1,81 & 0,35 & 1,24 & 3,41 \\
\hline Araucariaceae & Araucaria angustifolia (Bertol) O. Kuntze & & 8 & 6 & 0,41 & 1,92 & 0,75 & 3,08 \\
\hline Myrtaceae & Eugenia handroana D. Legrand & Euge ha & 18 & 9 & 0,93 & 0,88 & 1,12 & 2,93 \\
\hline Araliaceae & Schefflera morototoni (Aubl.) Maguire, Steyerm. \& Frodin & Sche mo & 12 & 7 & 0,62 & 1,42 & 0,87 & 2,91 \\
\hline Euphorbiaceae & Actinostemon concolor (Spreng.) Müll. Arg. & Actico & 30 & 9 & 1,55 & 0,23 & 1,12 & 2,90 \\
\hline Myrtaceae & Myrciaria floribunda (H. West ex Willd.) O. Berg. & Myrc fl & 18 & 12 & 0,93 & 0,25 & 1,49 & 2,68 \\
\hline Myrtaceae & Myrcia obtecta (O. Berg.) Kiaersk. & Myrc ob & 20 & 10 & 1,03 & 0,29 & 1,24 & 2,57 \\
\hline Lamiaceae & Vitex montevidensis Cham. & Vite mo & 11 & 8 & 0,57 & 0,97 & 1,00 & 2,53 \\
\hline Myrtaceae & Plinia rivularis (Cambess.) A.D. Rotman & Plin ri & 22 & 6 & 1,14 & 0,63 & 0,75 & 2,51 \\
\hline Myrtaceae & Myrcia arborescens $\mathrm{O}$. Berg & Myrc ar & 12 & 8 & 0,62 & 0,84 & 1,00 & 2,45 \\
\hline Rosaceae & Prunus myrtifolia (L.) Urb. & Prun my & 13 & 11 & 0,67 & 0,41 & 1,37 & 2,45 \\
\hline Euphorbiaceae & Sebastiania brasiliensis Spr. & Sebabr & 12 & 8 & 0,62 & 0,79 & 1,00 & 2,41 \\
\hline Euphorbiaceae & Gymnanthes cf. discolor (Spreng.) Müll. Arg. & Gymn di & 13 & 7 & 0,67 & 0,81 & 0,87 & 2,35 \\
\hline Lauraceae & Nectandra grandiflora Nees & & 9 & 7 & 0,47 & 0,97 & 0,87 & 2,31 \\
\hline Lauraceae & Lauraceae sp. 1 & & 7 & 5 & 0,36 & 1,23 & 0,62 & 2,21 \\
\hline Sapotaceae & Chrysophyllum marginatum (Hook \& Arn.) Radlk. & Chry ma & 10 & 6 & 0,52 & 0,85 & 0,75 & 2,11 \\
\hline Fabaceae & Calliandra selloi (Spreng.) J.F. Macbr. & Call se & 12 & 7 & 0,62 & 0,62 & 0,87 & 2,11 \\
\hline Arecaceae & Syagrus romanzoffiana (Cham.) Glassm. & & 7 & 6 & 0,36 & 0,95 & 0,75 & 2,06 \\
\hline Rubiaceae & Ixora venulosa Benth. & Ixorve & 15 & 9 & 0,78 & 0,14 & 1,12 & 2,04 \\
\hline Cactaceae & Cereus peruvianus (L.) J.S. Muell. & & 7 & 5 & 0,36 & 0,88 & 0,62 & 1,86 \\
\hline Fabaceae & Machaerium nyctitans (Vell.) Benth. & Mach ny & 10 & 5 & 0,52 & 0,68 & 0,62 & 1,82 \\
\hline
\end{tabular}


Tabela 1. Continuação.

\begin{tabular}{|c|c|c|c|c|c|c|c|c|}
\hline Famílias & Espécies & Cód. & NI & NA & DR & DoR & FR & IVI \\
\hline Fabaceae & Erythrina falcata Benth. & & 1 & 1 & 0,05 & 1,64 & 0,12 & 1,81 \\
\hline Annonaceae & Guatteria australis A. St.-Hil. & & 4 & 4 & 0,21 & 1,05 & 0,50 & 1,75 \\
\hline Meliaceae & Cedrela fissilis Vell. & & 9 & 4 & 0,47 & 0,72 & 0,50 & 1,68 \\
\hline Indeterminada & Indeterminada sp. 1 & & 8 & 3 & 0,41 & 0,82 & 0,37 & 1,61 \\
\hline Lauraceae & Ocotea diospyrifolia (Meisn.) Mez & & 6 & 4 & 0,31 & 0,78 & 0,50 & 1,59 \\
\hline Anacardiaceae & Lithraea molleoides (Vell.) Engl. & & 4 & 4 & 0,21 & 0,83 & 0,50 & 1,53 \\
\hline Myrtaceae & Psidium spathulatum Mattos & & 9 & 8 & 0,47 & 0,05 & 1,00 & 1,51 \\
\hline Aquifoliaceae & Ilex sp.1 & & 9 & 4 & 0,47 & 0,49 & 0,50 & 1,45 \\
\hline Apocynaceae & Aspidosperma polyneuron Müll. Arg. & Aspipo & 10 & 6 & 0,52 & 0,16 & 0,75 & 1,43 \\
\hline Moraceae & Ficus sp. 4 & & 2 & 2 & 0,10 & 1,00 & 0,25 & 1,35 \\
\hline Lauraceae & Cinnamomum sellowianum (Nees) Kosterm. & & 5 & 5 & 0,26 & 0,45 & 0,62 & 1,33 \\
\hline Melastomataceae & Miconia ligustroides (DC.) Naudin & & 7 & 5 & 0,36 & 0,27 & 0,62 & 1,26 \\
\hline Myrtaceae & Myrcia sp. 2 & Myrt & 12 & 4 & 0,62 & 0,13 & 0,50 & 1,24 \\
\hline Celastraceae & Maytenus evonymoides Reissek & & 7 & 6 & 0,36 & 0,06 & 0,75 & 1,17 \\
\hline Asteraceae & Gochnatia sp. 2 & & 5 & 3 & 0,26 & 0,44 & 0,37 & 1,07 \\
\hline Rubiaceae & Psychotria vellosiana Benth. & Psyc ve & 13 & 3 & 0,67 & 0,01 & 0,37 & 1,06 \\
\hline Salicaceae & Casearia lasiophylla Eichler & & 7 & 3 & 0,36 & 0,30 & 0,37 & 1,03 \\
\hline Moraceae & Ficus sp. 3 & & 6 & 4 & 0,31 & 0,20 & 0,50 & 1,01 \\
\hline Myrtaceae & Eugenia neoverrucosa Sobral & & 8 & 4 & 0,41 & 0,09 & 0,50 & 1,01 \\
\hline Nyctaginaceae & Guapira opposita (Vell.) Reitz & & 6 & 4 & 0,31 & 0,19 & 0,50 & 1,00 \\
\hline Lauraceae & Ocotea silvestris Vattimo-Gil & & 4 & 4 & 0,21 & 0,25 & 0,50 & 0,96 \\
\hline Thymelaeaceae & Daphnopsis racemosa Griseb & & 7 & 4 & 0,36 & 0,06 & 0,50 & 0,92 \\
\hline Meliaceae & Guarea macrophylla Vahl. & & 3 & 3 & 0,16 & 0,34 & 0,37 & 0,87 \\
\hline Fabaceae & Bauhinia forficata Link & & 3 & 3 & 0,16 & 0,32 & 0,37 & 0,85 \\
\hline Rubiaceae & Chomelia cf obtusa Cham. \& Schltdl. & & 4 & 4 & 0,21 & 0,08 & 0,50 & 0,78 \\
\hline Myrtaceae & Myrcia venulosa DC. & & 5 & 4 & 0,26 & 0,03 & 0,50 & 0,78 \\
\hline Euphorbiaceae & Croton floribundus Spreng. & & 4 & 3 & 0,21 & 0,20 & 0,37 & 0,78 \\
\hline Fabaceae & Machaerium sp. 2 & & 1 & 1 & 0,05 & 0,60 & 0,12 & 0,78 \\
\hline Vochysiaceae & Qualea cordata Spreng. & & 3 & 3 & 0,16 & 0,24 & 0,37 & 0,77 \\
\hline Annonaceae & Rollinia sylvatica (A. St.-Hil.) Mart. & & 4 & 3 & 0,21 & 0,17 & 0,37 & 0,75 \\
\hline Lauraceae & Lauraceae sp. 2 & & 1 & 1 & 0,05 & 0,57 & 0,12 & 0,75 \\
\hline Myrtaceae & Eugenia ramboi D. Legrand & & 6 & 3 & 0,31 & 0,03 & 0,37 & 0,71 \\
\hline Aquifoliaceae & Ilex cf amara Loes. & & 1 & 1 & 0,05 & 0,51 & 0,12 & 0,69 \\
\hline Lauraceae & Lauraceae sp. 6 & & 5 & 3 & 0,26 & 0,04 & 0,37 & 0,68 \\
\hline Sapindaceae & Cupania vernalis Cambess. & & 3 & 3 & 0,16 & 0,14 & 0,37 & 0,67 \\
\hline Salicaceae & Salicaceae sp. & & 1 & 1 & 0,05 & 0,48 & 0,12 & 0,66 \\
\hline Vochysiaceae & Vochysia sp. & & 4 & 3 & 0,21 & 0,07 & 0,37 & 0,65 \\
\hline Myrtaceae & Campomanesia guazumifolia (Cambess.) O. Berg. & & 5 & 2 & 0,26 & 0,10 & 0,25 & 0,61 \\
\hline Indeterminada & Indeterminada sp. 2 & & 3 & 3 & 0,16 & 0,07 & 0,37 & 0,60 \\
\hline Hippocrateaceae & Hippocrateaceae sp. & & 6 & 2 & 0,31 & 0,03 & 0,25 & 0,59 \\
\hline Aquifoliaceae & Ilex sp. 2 & & 6 & 2 & 0,31 & 0,02 & 0,25 & 0,58 \\
\hline Clethraceae & Clethra scabra Pers. & & 4 & 2 & 0,21 & 0,11 & 0,25 & 0,57 \\
\hline Lauraceae & Ocotea sp. 3 & & 3 & 2 & 0,16 & 0,14 & 0,25 & 0,55 \\
\hline Euphorbiaceae & Croton sp. 2 & & 1 & 1 & 0,05 & 0,37 & 0,12 & 0,54 \\
\hline
\end{tabular}


Tabela 1. Continuação.

\begin{tabular}{|c|c|c|c|c|c|c|c|c|}
\hline Famílias & Espécies & Cód. & NI & NA & $\mathrm{DR}$ & DoR & FR & IVI \\
\hline Arecaceae & Geonoma schottiana (Aubl.) Maguire, Steyerm. \& Frodim & & 3 & 2 & 0,16 & 0,08 & 0,25 & 0,48 \\
\hline Malvaceae & Luehea divaricata Mart. & & 2 & 2 & 0,10 & 0,07 & 0,25 & 0,42 \\
\hline Rutaceae & Zanthoxylum sp. & & 3 & 2 & 0,16 & 0,02 & 0,25 & 0,42 \\
\hline Asteraceae & Piptocarpha angustifolia Dusén & & 3 & 2 & 0,16 & 0,01 & 0,25 & 0,41 \\
\hline Euphorbiaceae & Croton sp. 1 & & 2 & 2 & 0,10 & 0,05 & 0,25 & 0,40 \\
\hline Myrtaceae & Pimenta pseudocaryophyllus (Gomes) L. R. Landrum & & 2 & 2 & 0,10 & 0,04 & 0,25 & 0,39 \\
\hline Lythraceae & Lafoensia pacari A. St.-Hil. & & 2 & 2 & 0,10 & 0,03 & 0,25 & 0,38 \\
\hline Rubiaceae & Alibertia myrciifolia Spruce ex Schum. & & 2 & 2 & 0,10 & 0,01 & 0,25 & 0,37 \\
\hline Lauraceae & Persea wildenovii Kosterm. & & 1 & 1 & 0,05 & 0,19 & 0,12 & 0,36 \\
\hline Lauraceae & Ocotea pulchella (Nees) Mez & & 1 & 1 & 0,05 & 0,19 & 0,12 & 0,36 \\
\hline Melastomataceae & Leandra petropolitana Cogn. & & 2 & 2 & 0,10 & 0,00 & 0,25 & 0,36 \\
\hline Myrtaceae & Myrcia hatschbachii D. Legrand & & 2 & 2 & 0,10 & 0,00 & 0,25 & 0,35 \\
\hline Fabaceae & Ormosia arborea (Vell.) Harms & & 2 & 1 & 0,10 & 0,12 & 0,12 & 0,35 \\
\hline Sapindaceae & Matayba elaegnoides Radlk & & 1 & 1 & 0,05 & 0,15 & 0,12 & 0,33 \\
\hline Ebenaceae & Diospyros hispida DC. & & 1 & 1 & 0,05 & 0,14 & 0,12 & 0,32 \\
\hline Urticaceae & Cecropia sp. & & 1 & 1 & 0,05 & 0,13 & 0,12 & 0,31 \\
\hline Cunoniaceae & Lamanonia ternata Vell. & & 2 & 1 & 0,10 & 0,06 & 0,12 & 0,28 \\
\hline Indeterminada & Indeterminada sp. 3 & & 1 & 1 & 0,05 & 0,11 & 0,12 & 0,28 \\
\hline Fabaceae & Machaerium aculeatum Raddi & & 1 & 1 & 0,05 & 0,09 & 0,12 & 0,27 \\
\hline Rosaceae & Prunus sp. & & 2 & 1 & 0,10 & 0,02 & 0,12 & 0,25 \\
\hline Elaeocarpaceae & Sloanea lasiocoma K. Schum. & & 2 & 1 & 0,10 & 0,02 & 0,12 & 0,25 \\
\hline Annonaceae & Guateria nigrescens Mart. & & 1 & 1 & 0,05 & 0,07 & 0,12 & 0,24 \\
\hline Lauraceae & Ocotea sp. 2 & & 1 & 1 & 0,05 & 0,07 & 0,12 & 0,24 \\
\hline Lauraceae & Cryptocarya sp. & & 1 & 1 & 0,05 & 0,06 & 0,12 & 0,24 \\
\hline Euphorbiaceae & Croton sp. 3 & & 2 & 1 & 0,10 & 0,01 & 0,12 & 0,23 \\
\hline Solanaceae & Solanaceae sp. & & 1 & 1 & 0,05 & 0,05 & 0,12 & 0,22 \\
\hline Solanaceae & Solanum argenteum Dunal & & 1 & 1 & 0,05 & 0,04 & 0,12 & 0,22 \\
\hline Bignoniaceae & Tabebuia chrysotrycha (Mart. ex A. DC.) Standl. & & 1 & 1 & 0,05 & 0,04 & 0,12 & 0,22 \\
\hline Euphorbiaceae & Sapium glandulatum (Vell.) Pax & & 1 & 1 & 0,05 & 0,03 & 0,12 & 0,20 \\
\hline Meliaceae & Trichilia elegans A. Juss. & & 1 & 1 & 0,05 & 0,02 & 0,12 & 0,19 \\
\hline Meliaceae & Trichilia claussenii C. DC. & & 1 & 1 & 0,05 & 0,01 & 0,12 & 0,19 \\
\hline Lauraceae & Ocotea sp. 4 & & 1 & 1 & 0,05 & 0,01 & 0,12 & 0,19 \\
\hline Myrtaceae & Myrcia sp. 1 & & 1 & 1 & 0,05 & 0,01 & 0,12 & 0,19 \\
\hline Boraginaceae & Cordia ecalyculata Vell. & & 1 & 1 & 0,05 & 0,01 & 0,12 & 0,19 \\
\hline Bignoniaceae & Jacaranda puberula Cham. & & 1 & 1 & 0,05 & 0,01 & 0,12 & 0,18 \\
\hline Sapotaceae & Chrysophyllum gonocarpum (Mart. \& Eichl.) Engl. & & 1 & 1 & 0,05 & 0,01 & 0,12 & 0,18 \\
\hline Indeterminada & Indeterminada sp. 4 & & 1 & 1 & 0,05 & 0,00 & 0,12 & 0,18 \\
\hline Elaeocarpaceae & Sloanea cf garckeana K. Schum. & & 1 & 1 & 0,05 & 0,00 & 0,12 & 0,18 \\
\hline Erythroxylaceae & Erythroxylum deciduum A. St.-Hil. & & 1 & 1 & 0,05 & 0,00 & 0,12 & 0,18 \\
\hline Myrtaceae & Myrciaria delicatula (DC.) O. Berg. & & 1 & 1 & 0,05 & 0,00 & 0,12 & 0,18 \\
\hline Annonaceae & Rollinia sp. & & 1 & 1 & 0,05 & 0,00 & 0,12 & 0,18 \\
\hline Asteraceae & Piptocarpha axillaris (Less.) Baker & & 1 & 1 & 0,05 & 0,00 & 0,12 & 0,18 \\
\hline Ericaceae & Agarista pulchella (Cham.) ex G. Don & & 1 & 1 & 0,05 & 0,00 & 0,12 & 0,18 \\
\hline Solanaceae & Cestrum strigilatum Ruiz \& Pav. & & 1 & 1 & 0,05 & 0,00 & 0,12 & 0,18 \\
\hline Lauraceae & Ocotea sp. 1 & & 1 & 1 & 0,05 & 0,00 & 0,12 & 0,18 \\
\hline
\end{tabular}


uma das espécies mais abundante na Floresta Estacional Semidecidual, a densidade absoluta foi de 20 ind./ha.

Comparando a estrutura da vegetação nas amostras dos capões e da floresta de galeria, mostrou-se que 42 espécies foram comuns aos dois locais, 29 encontrou-se apenas na floresta de galeria, enquanto que 72 foram amostradas exclusivamente nos capões. A vegetação dos capões mostrou uma maior diversidade e valores de densidade e área basal superiores aos encontrados para àquela que margeia o rio Iapó (Tab. 2). No entanto, a distribuição dos indivíduos pelas espécies (J) foi maior para a floresta de galeria.

\section{Comparações florísticas}

Através da análise comparativa de 29 áreas florestais estudadas para o estado do Paraná (Tab. 3), incluindo o presente trabalho, pode-se observar através do dendograma (Fig. 4) que estas formam dois grandes grupos. O primeiro grupo, maior e caracterizado pela heterogeneidade, formou-se exclusivamente por áreas de Floresta Ombrófila Mista (ver Tab. 3). O segundo grupo apresentou dois subgrupos, um constituído predominantemente de remanescentes de Floresta Estacional Semidecidual (a área FMA é a única exceção), e um outro, o qual inclui o PEG, representado por locais situados no segundo planalto paranaense, com áreas tradicionalmente classificadas como Floresta Ombrófila Mista, mas que estão sob influência da Estacional.

\section{Grupo de espécies e zonações}

Os autovalores obtidos da CCA para os eixos 1 e 2 foram 0,36 e 0,21 , respectivamente. Estes valores são considerados baixos ( $<0,5$ - ter Braak 1995), indicando a predominância da variação nas abundâncias das espécies. Os dois primeiros eixos da CCA explicaram em conjunto apenas 12,5\% (eixo 1, $7,9 \%$ e eixo $2,4,6 \%$ ) da variância dos dados, portanto, uma grande proporção da variância permaneceu sem explicação.

Por outro lado, as co-relações entre espécies-composição do solo foram altas para os dois primeiros eixos da CCA: 0,87 (eixo 1) e 0,83 (eixo 2). Além disso, o teste de permutação de Monte Carlo $(P<0,05)$ indicou que estas co-relações foram significativas para estes dois eixos.

A CCA ordenou dois grupos distintos: um formado pelas parcelas distribuídas nos capões (principalmente à esquerda do eixo 1), e outro pelas parcelas alocadas na floresta de galeria (à direita do eixo 1) (Fig. 5).

O primeiro eixo esteve relacionado fortemente à textura do solo, com areia associada positivamente e a argila e $\mathrm{Al}$ negativamente (Tab. 4). Já o segundo eixo esteve associado principalmente com a disponibilidade de nutrientes, apresentando correlação positiva com areia, $\mathrm{Al}$ e m, enquanto $\mathrm{Mg}$ teve correlação negativa.

Portanto, a textura e a acidez dos solos foram as principais propriedades que determinaram esses dois grupos. A floresta de galeria foi relacionada a solos arenosos, enquanto os capões estiveram associados a solos mais ácidos e de textura argilosa, formando dois subgrupos: um com ambientes de solos álicos $(\mathrm{Al}, \mathrm{m})$ e outro com solos mais férteis $(\mathrm{Mg})$.

A ordenação das espécies pela CCA (Fig. 6) sugere que Callisthene major, Machaerium nyctitans, Sebastiania schottiana, S. brasiliensis, Calliandra selloi e Inga vera estiveram relacionadas à ambientes com solos arenosos distribuídas principalmente ao longo da floresta de galeria. Nas unidades amostrais estabelecidas em capões com alta acidez estiveram Psychotria vellosiana, Schefflera morototoni e Myrciaria cuspidata, relacionadas com m e as espécies Myrcia sp. 2, Plinia rivulares, Myrcia multiflora e Casearia obliqua relacionadas à ambientes argilosos com alta concentração de Al. No entanto, Coussaria sp., Alchornea triplinervia, Casearia sylvestris, Chrysophylum marginata e Actinostemon concolor estiveram preferencialmente em parcelas distribuídas nos capões com presença de solos mais férteis, com alta concentração de Mg.

\section{Discussão}

As famílias mais representativas em número de espécies neste estudo são as mesmas encontradas em áreas de Floresta Ombrófila Mista (Nakajima et al. 1996; Dias et al. 1998), onde é notável a riqueza de espécies de Myrtaceae e Lauraceae (Jarenkow et al. 1987; Silva \& Marconi 1990; Koehler et al. 1998; Galvão et al. 1989), sendo que Fabaceae, Euphorbiaceae e Rubiaceae também têm grande expressividade nesta formação (Nakajima et al. 1996; Dias et al. 1998). Portanto, a prevalência dessas famílias em número de espécies caracteriza as florestas com Araucaria angustifolia no planalto meridional brasileiro.

Contudo, é marcante a variação em nível específico, como observado nas diferentes florestas estudadas em tal formação no estado do Paraná (Fig. 4), onde as baixas similaridades podem estar associadas as grandes variações dos ambientes encontradas nas áreas analisadas. Características como inundação, estágios sucessionais diferentes e zona de contato com outras associações vegetais são relatados como determinantes para dissimilaridade florística destas formações, mesmo em áreas geograficamente próximas (Fig. 4) (Klein 1960; Klein \& Hatschbach 1971).

Tabela 2. Parâmetros comparativos entre os capões e a floresta de galeria do Parque Estadual do Guartelá, Tibagi, PR.

\begin{tabular}{ccc}
\hline Descritores & Capões & Galeria \\
\hline Número de parcelas & 30 & 20 \\
Número de indivíduos & 1235 & 698 \\
Número de espécies & 111 & 72 \\
Número de famílias & 40 & 37 \\
Densidade total (ind./ha.) & 4.117 & 3.490 \\
Área basal total (m²/ha.) & 43,24 & 51,50 \\
Índice de diversidade (H') & 3,89 & 3,62 \\
Índice de equabilidade (J) & 0,83 & 0,85 \\
\hline
\end{tabular}


Tabela 3. Estudos em áreas florestais do Estado do Paraná. FF- formação florestal: FOM- Floresta Ombrófila Mista; FOMA- Floresta Ombrófila Mista Aluvial; FESFloresta Estacional Semidecidual; FESA- Floresta Estacional Semidecidual Aluvial. NE- número de espécies selecionadas para análise.

\begin{tabular}{|c|c|c|c|c|c|c|c|c|}
\hline Cód. & Localidade & Município & Coordenada & Alt. (m) & FF & Clima & $\mathrm{NE}$ & Autores \\
\hline VRB & Várzea do Bitumirim & Ipiranga & & 806 & FOMA & $\mathrm{Cfb}$ & 36 & Silva et al. 1992 \\
\hline SMS & Fazenda do Durgo & S. Mateus do Sul & $25^{\circ} 52^{\prime}$ S e $50^{\circ} 23^{\prime} \mathrm{W}$ & 760 & FOM & $\mathrm{Cfb}$ & 104 & Britez et al. 1995 \\
\hline VRI & Várzea do rio Iguaçu & S. Mateus do Sul & $25^{\circ} 52^{\prime}$ S e $50^{\circ} 23^{\prime} \mathrm{W}$ & 760 & FOMA & $\mathrm{Cfb}$ & 55 & Silva et al. 1997 \\
\hline FNI & Floresta Nacional de Irati & Teixeira Soares & & 870 & FOM & $\mathrm{Cfb}$ & 99 & Galvão et al. 1992 \\
\hline FGA & Fazenda Gralha Azul & Faz.Rio Grande & $25^{\circ} 37^{\prime} \mathrm{S}$ e $49^{\circ} 45^{\prime} \mathrm{W}$ & 870 & FOM & $\mathrm{Cfb}$ & 57 & Koehler et al. 1998 \\
\hline SJT & Estação experim. UFPR & S. J. do Triunfo & $25^{\circ} 34^{\prime}$ S e $50^{\circ} 05^{\prime} \mathrm{W}$ & 780 & FOM & $\mathrm{Cfb}$ & 37 & Sanquetta \& Corte 1998 \\
\hline JB & Jardim Botânico & Curitiba & $25^{\circ} 25^{\prime}$ S e $49^{\circ} 17^{\prime} \mathrm{W}$ & 900 & FOM & $\mathrm{Cfb}$ & 36 & Cervi et al. 1989 \\
\hline FTC & Fazenda 3 Capões & Guarapuava & $25^{\circ} 24^{\prime}$ S e $51^{\circ} 40^{\prime} \mathrm{W}$ & 989 & FOM & $\mathrm{Cfb}$ & 48 & Silva (dados não publicados) \\
\hline PA & $\mathrm{P}$ das Araucárias & Guarapuava & $25^{\circ} 21^{\prime}$ S e $51^{\circ} 27^{\prime} \mathrm{W}$ & 1098 & FOM & $\mathrm{Cfb}$ & 36 & Silva (dados não publicados) \\
\hline COL1 & Colombo & Colombo & $25^{\circ} 20^{\prime}$ S e $49^{\circ} 14^{\prime} \mathrm{W}$ & 920 & FOM & $\mathrm{Cfb}$ & 43 & Silva \& Marconi 1990 \\
\hline COL2 & U. P.florestal Centro-Sul & Colombo & $25^{\circ} 20^{\prime}$ S e $49^{\circ} 14^{\prime} \mathrm{W}$ & 920 & FOM & $\mathrm{Cfb}$ & 53 & Oliveira \& Rotta 1982 \\
\hline CI & Capão da Imbui & Curitiba & & & FOM & $\mathrm{Cfb}$ & 36 & Dombrowski \& Kuniyoshi 1967 \\
\hline PEVV & P E Vila Velha & Ponta Grossa & $25^{\circ} 15^{\prime}$ S e $50^{\circ} 05^{\prime} \mathrm{W}$ & 916 & FOM & $\mathrm{Cfb}$ & 95 & Ramos (dados não publicados) \\
\hline RQP & Rio Quebra-Perna & Ponta Grossa & $25^{\circ} 08^{\prime} \mathrm{S}$ e $49^{\circ} 58^{\prime} \mathrm{W}$ & & FOMA & $\mathrm{Cfb}$ & 59 & Oliveira (dados não publicados) \\
\hline RCC & Rio Cara-Cara & Ponta Grossa & $25^{\circ} 09^{\prime}$ S e $50^{\circ} 07^{\prime} \mathrm{W}$ & 780 & FOM & $\mathrm{Cfb}$ & 34 & Moro et al. 2001 \\
\hline RSJ & Rio São Jorge & Ponta Grossa & $25^{\circ} 06^{\prime}$ S e $50^{\circ} 04^{\prime} \mathrm{W}$ & 1110 & FOMA & $\mathrm{Cfb}$ & 40 & Moro et al. 1996 \\
\hline PMBR & P. M. Boca da Ronda & Ponta Grossa & & & FOM & $\mathrm{Cfb}$ & 57 & Takeda et al. 1998 \\
\hline PEG & P. E. Guartelá & Tibagi & $24^{\circ} 39 \mathrm{~S}$ e $5015^{\prime} \mathrm{W}$ & 1150 & FOM & $\mathrm{Cfa}$ & 113 & Presente estudo \\
\hline $\mathrm{FB}$ & Fazenda Batavo & Tibagi & $24^{\circ} 31^{\prime} \mathrm{S}$ e $50^{\circ} 25^{\prime} \mathrm{W}$ & 700 & FOMA & $\mathrm{Cfa}$ & 131 & Dias et al. 1998 \\
\hline FMA & Fazenda Monte Alegre & Telêmaco Borba & $24^{\circ} 20^{\prime}$ S e $50^{\circ} 37^{\prime} \mathrm{W}$ & 606 & FOMA & $\mathrm{Cfa}$ & 89 & Nakajima et al. 1996 \\
\hline PETB & Parque Ecológico & Telêmaco Borba & $24^{\circ} 18^{\prime}$ S e $50^{\circ} 35^{\prime} \mathrm{W}$ & 885 & FOM & $\mathrm{Cfb}$ & 40 & Vargas (dados não publicados) \\
\hline FCR & Faz. C. do Restingão & Jaguariaíva & $24^{\circ} 19^{\prime} \mathrm{S}$ e $49^{\circ} 37^{\prime} \mathrm{W}$ & 1130 & FOMA & $\mathrm{Cfb}$ & 73 & Souza (dados não publicados) \\
\hline FBS & Fazenda Bom Sucesso & Sapopema & $24^{\circ} 01^{\prime}$ S e $50^{\circ} 41^{\prime} \mathrm{W}$ & 780 & FESA & $\mathrm{Cfa}$ & 109 & Silva et al. 1995 \\
\hline PMG-C & P E Mata dos Godoy & Londrina & $23^{\circ} 27^{\prime}$ S e $51^{\circ} 15^{\prime} \mathrm{W}$ & 500 & FESA & $\mathrm{Cfa}$ & 85 & Soares-Silva et al. 1998 \\
\hline PMG-A & P E Mata dos Godoy & Londrina & $23^{\circ} 27^{\prime}$ S e $51^{\circ} 15^{\prime} \mathrm{W}$ & 500 & FESA & $\mathrm{Cfa}$ & 60 & Bianchini et al. 2003 \\
\hline PMG-T & P E Mata dos Godoy & Londrina & $23^{\circ} 27^{\prime}$ S e $51^{\circ} 15^{\prime} \mathrm{W}$ & 500 & FES & $\mathrm{Cfa}$ & 80 & Silveira (dados não publicados) \\
\hline PMG-N & P E Mata dos Godoy & Londrina & $23^{\circ} 27^{\prime}$ S e $51^{\circ} 15^{\prime} \mathrm{W}$ & 600 & FES & $\mathrm{Cfa}$ & 93 & Soares-Silva \& Barroso 1992 \\
\hline FD-C & Fazenda Doralice & Ibiporã & $23^{\circ} 16^{\prime}$ S e $51^{\circ} 01^{\prime} \mathrm{W}$ & 480 & FESA & $\mathrm{Cfa}$ & 92 & Soares-Silva et al. 1992 \\
\hline FD-P & Fazenda Doralice & Ibiporã & $23^{\circ} 16^{\prime}$ S e $51^{\circ} 01^{\prime} \mathrm{W}$ & 480 & FES & $\mathrm{Cfa}$ & 115 & Carmo (dados não publicados) \\
\hline
\end{tabular}

A análise global da estrutura nas áreas florestadas do PEG revelou uma vegetação com distribuição relativamente equilibrada dos indivíduos entre as espécies, já que as dez mais importantes somaram $30,10 \%$, um valor consideravelmente baixo quando comparado com outros estudos (e.g. Jarenkow et al. 1987; Rondon Neto et al. 2002) o que refletiu nos maiores valores de diversidade dos fragmentos estudados.

Assim, foram encontrados um grande número de espécies e uma elevada diversidade para as áreas estudadas no PEG, analisadas tanto para a amostra total (indivíduos maiores que $3 \mathrm{~m}$ de altura) como selecionando apenas os espécimes com DAP $\geq 5 \mathrm{~cm}$. Estes valores de diversidade estão acima daqueles relatados dentro das áreas de domínio da Floresta Ombrófila Mista do Paraná (Silva et al. 1992; Nakajima et al. 1996; Dias et al. 1998; Moro et al. 2001), bem como para o Rio Grande do Sul (Rondon Neto et al. 2002).

Os altos valores comparados aos estudos citados anteriormente podem estar sendo influenciados pelos procedimentos de amostragem, pois as unidades amostrais foram distribuídas ao longo de todo parque, com alta variação de ambientes. Nota-se, entretanto, que o elevado número em espécies se caracteriza também pela mistura de duas formações florestais distintas: a Ombrófila Mista, com ocorrência típica da Araucaria angustifolia, que por si só caracteriza esta formação (Reitz \& Klein 1966) e pela Estacional Se- 


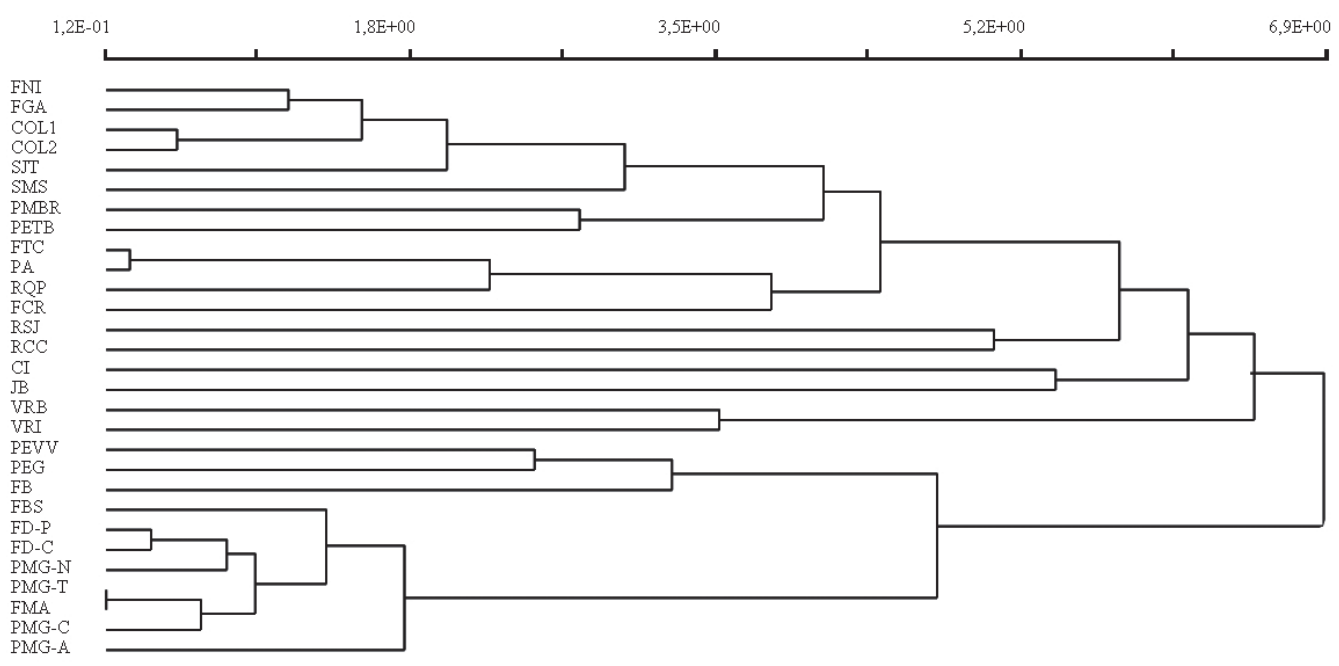

Figura 4. Dendograma mostrando os grupos obtidos pelo Coeficiente de Similaridade de Jaccard e usando média de grupo como método de agrupamento, em áreas de Florestas Ombrófila Mista e Estacional Semidecidual para o estado do Paraná.

midecidual representada, por exemplo, por Aspidosperma polyneuron, uma das espécies com maior densidade nas florestas do norte do estado (Silva \& Soares-Silva 2000; Soares-Silva \& Barroso 1992). Na área estudada encontrou-se uma baixa densidade destas espécies, sugerindo que os elementos mais característicos destas formações são menos expressivos em função da região ecotonal.

Tal característica demonstra que as áreas de florestas do PEG formam um ecótono das duas formações mais ocorrentes no referido estado, estando bem ilustrada no dendrograma (Fig. 4), onde a análise de agrupamento (UPGMA) revelou uma maior similaridade com as Florestas Estacionais Semideciduais. Com exceção do Parque Estadual de Vila Velha (PEVV), as áreas de Floresta Ombrófila Mista que formaram o subgrupo juntamente com o PEG (Fig. 4) ocorrem em regiões onde o clima é do tipo Cfa (subtropical), diferindo das demais florestas paranaenses desta formação, pois apresentam clima predominantemente do tipo $\mathrm{Cfb}$ (temperado). Assim, é possível que o clima com médias de temperatura mais elevadas esteja contribuindo para o processo sucessional destas áreas, onde os elementos típicos da Floresta Ombrófila Mista estariam paulatinamente sendo substituídas pelas espécies da Floresta Estacional Semidecidual (Klein 1960; Maack 1981).

Estas florestas encontradas no PEG desenvolveram-se em solos de composição variada, onde predominam os Neossolos litólicos que estão associados aos Cambissolos háplicos e afloramentos rochosos. Pelos resultados, é notório que a textura e acidez estiveram relacionadas com a distribuição de abundância das espécies. Trabalhos recentes têm mostrado que propriedades químicas e estruturais dos solos, muitas vezes associadas a outras variações ambientais, têm um papel fundamental na distribuição espacial de muitas espécies de florestas brasileiras (Cardoso \& Schiavini 2002; Oliveira Filho et al. 2004).
Os capões estudados no PEG apresentaram solos de textura argilosa com variações químicas, que propiciaram o estabelecimento de populações adaptadas a cada microambiente, formado por dois subgrupos de parcelas distintas, resultando em uma maior diversidade de espécies. As unidades amostrais dos capões, estabelecidas ao acaso, abrangeram principalmente ambientes que tiveram correlacionado as variáveis concentração e saturação por alumínio, sugerindo que estas áreas são mais abundantes no parque. Portanto, a alta acidez não representa um fator limitante para o desenvolvimento da vegetação florestal, com ocorrência de muitas espécies que tiveram correlacionadas, como Psychotria vellosiana, Schefflera morototoni, Casearia obliqua, além das mirtáceas Myrciaria cuspidata, Plinia rivulares, Myrcia multiflora. Por outro lado, a maior fertilidade do solo, caracterizado pelo $\mathrm{Mg}$, teve relacionada fortemente com a argila, ocorrendo principalmente as espécies Actinostemon concolor, Casearia sylvestris e Chrysophyllum marginatum que apresentam ampla distribuição nas florestas Estacionais Semideciduais e Ombrófila Mista encontradas ao longo de toda Bacia do rio Tibagi-PR (Dias et al. 2002).

A floresta de galeria desenvolvida sob solos arenosos rasos, provindo das escarpas rochosas do Arenito Furnas, apresentou uma estrutura arbórea menos densa e com menor valor de diversidade. Estudos têm mostrado a diminuição no número de indivíduos e de espécies ao longo de um gradiente ao alcançar florestas adjacentes à cursos d'água (Bianchini et al. 2003), pela seletividade das condições marginais. Porém, na área de estudo não deve ser este fator que está determinando uma menor diversidade, pois as características do rio Iapó ao longo do parque, bem encaixado pela formação do canyon, permitem que somente as plantas que habitam a estreita faixa ecotonal entre os ambientes aquático e terrestre estejam sob influência direta das condições hídricas. Portanto, apesar da alta densidade 


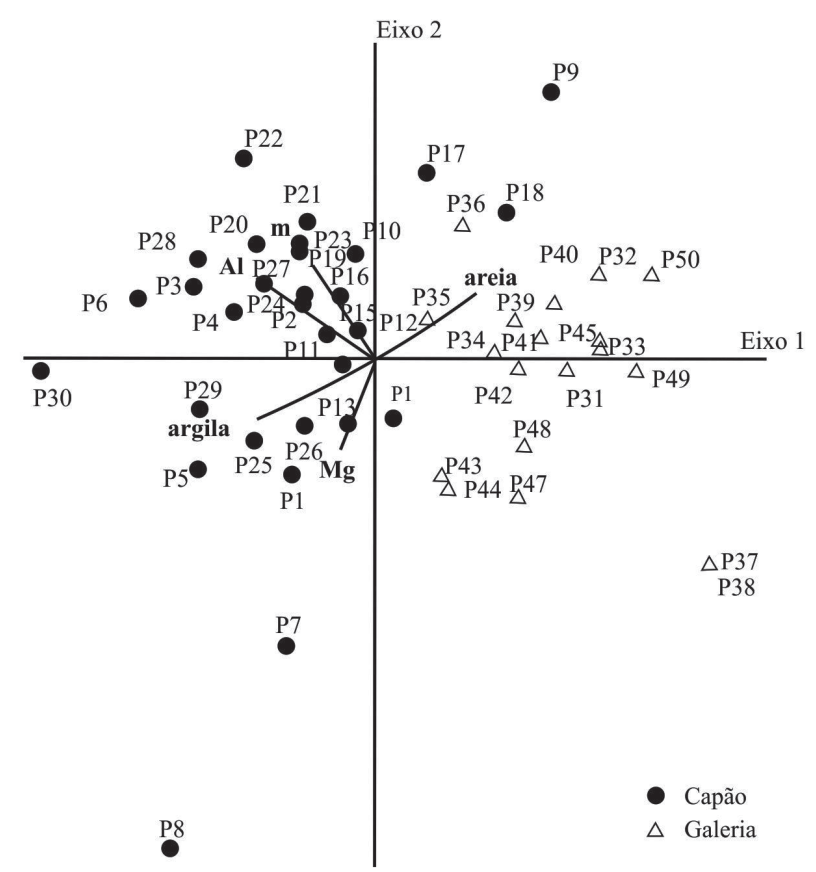

Figura 5. Diagrama de ordenação das parcelas pela análise de correspondência canônica (CCA), baseado na distribuição do número de indivíduos de 45 espécies em 50 parcelas das florestas do Parque Estadual do Guartelá, Tibagi, PR, e suas correlações com varáveis do solo.

de espécies como Sebastiania schottiana e Inga vera, típicas de beira de rio, espécies consideradas xerófitas como Cereus peruvianus e Callisthene major, foram amostradas evidenciando a total ausência da influência hídrica em alguns trechos. Maack (1968) utiliza o termo pseudomatas de galeria para designar tais condições na região dos Campos Gerais, pois esta vegetação arbórea não estaria condicionada à busca de umidade.

Espécies como Pilocarpus pauciflorus, Myrcia breviramis, Soroceae bonplandii, Vitex montevidensis, Ixora venulosa e Roupala brasiliensis tiveram baixa correlação com as características edáficas analisadas, ocorrendo em toda área de estudo.

Outros fatores, além da composição do solo, exercem forte influência na distribuição das espécies tais como: topografia, relações hídricas, incidência de luz e alteração antrópica. Estas variáveis, apesar de não avaliadas, devem

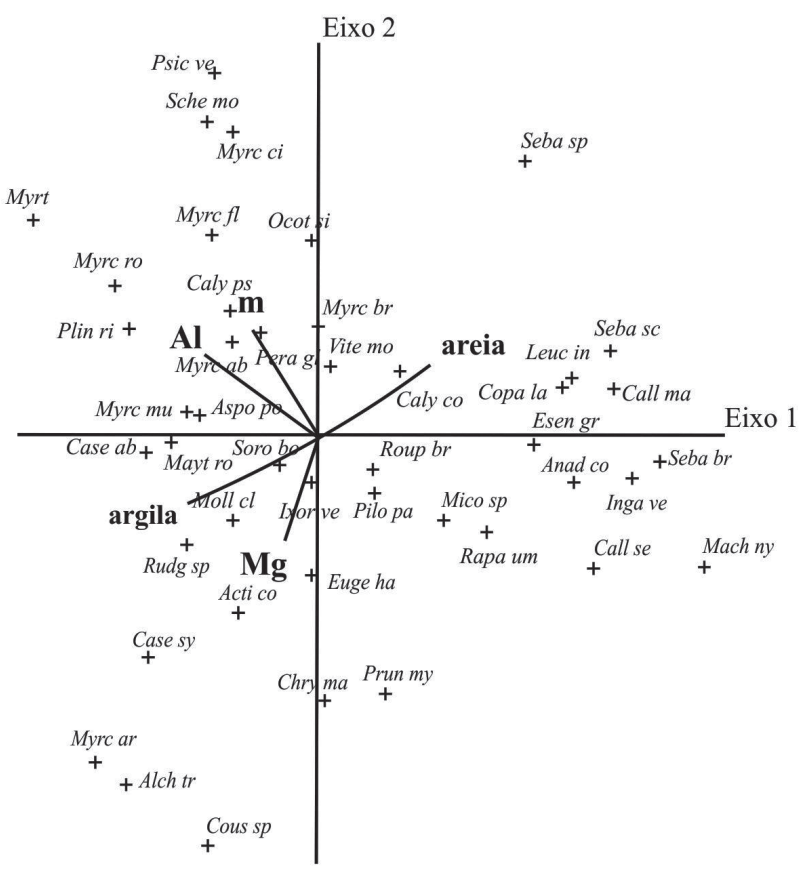

Figura 6. Diagrama de ordenação de espécies pela análise de correspondência canônica (CCA), baseado na distribuição do número de indivíduos de 45 espécies em 50 parcelas das florestas do Parque Estadual do Guartelá, Tibagi, PR, e suas correlações com varáveis do solo. Os nomes das espécies correspondentes as abreviações encontram-se na tabela 1.

estar determinando a distribuição espacial de muitas espécies, já que para características edáficas, a porcentagem de variância explicada pelos eixos da CCA foi baixa.

A floresta Ombrófila Mista naturalmente fragmentada dentro dos limites do PEG está localizada em uma região marcadamente relacionada por heterogeneidade de ambientes influenciada pelas transições climáticas, topográficas e vegetacionais, formando ecótono com as formações campestre e savânica e ainda, sob influência do avanço da floresta Estacional Semidecidual. Este conjunto de fatores resultou em uma alta diversidade de espécies arbóreas, quando comparada com áreas contínuas relatadas pela literatura; além disso, as características edáficas analisadas neste estudo, apesar de alcançar baixos valores, estão contribuindo para a distribuição das populações ocorrentes na floresta de galeria e ao longo dos capões presentes no parque.

Tabela 4. Matriz de correlação entre as variáveis do solo e os dois primeiros eixos da análise de correspondência canônica (CCA) (A) e as correlações entre as variáveis do solo (B) em 50 parcelas distibuídas nas florestas do Parque Estadual do Guartelá, Tibagi, PR.

\begin{tabular}{|c|c|c|c|c|c|c|c|}
\hline & \multicolumn{2}{|c|}{ A } & \multicolumn{5}{|c|}{$B$} \\
\hline & Eixo 1 & Eixo 2 & Areia & Argila & $\mathrm{Al}$ & $\mathrm{Mg}$ & $\mathrm{P}$ \\
\hline areia & 0,596 & 0,424 & & & & & \\
\hline Argila & $-0,711$ & $-0,384$ & $-0,885$ & & & & \\
\hline $\mathrm{Al}$ & $-0,640$ & 0,473 & $-0,376$ & 0,351 & & & \\
\hline $\mathrm{Mg}$ & $-0,212$ & $-0,589$ & $-0,430$ & 0,588 & $-0,271$ & & \\
\hline $\mathrm{P}$ & 0,509 & $-0,012$ & 0,051 & $-0,243$ & $-0,295$ & $-0,092$ & \\
\hline $\mathrm{m}$ & $-0,380$ & 0,615 & $-0,003$ & 0,013 & 0,811 & $-0,580$ & $-0,295$ \\
\hline
\end{tabular}




\section{Agradecimentos}

Os autores agradecem ao Instituto Ambiental do Paraná (IAP) pela autorização concedida para realização deste estudo e aos moradores do entorno do PEG por permitir a entrada em suas propriedades; ao Dr. Aloysio de P. Teixeira pela revisão nas análises estatísticas; a Gisele A. D. S. Santos e Anna Luiza P. Andrade pela preciosa ajuda nos trabalhos de campo.

\section{Referências Bibliográficas}

Bianchini, E.; Popolo, R.S.; Dias, M.C. \& Pimenta, J.P. 2003. Diversidade e estrutura de espécies arbóreas em área alagável do município de Londrina, Sul do Brasil. Acta Botânica Brasílica 17(3): 405-419.

Britez, R.M., Silva, S.M., Souza, W.S. \& Motta, J.T.W. 1995. Levantamento florístico em Floresta Ombrófila Mista, São Mateus do Sul, Paraná, Brasil. Arquivos de Biologia e Tecnologia 38(4): 1147-1161.

Cardoso, E. \& Schiavini, I. 2002. Relação entre distribuição de espécies arbóreas e topografia em um gradiente florestal na Estação Ecológica do Panga (Uberlância, MG). Revista Brasileira de Botânica 25: 277-289.

Castelha, P.R. \& Britez, R.M.A. 2004. Floresta de Araucária no Paraná Conservação e diagnóstico dos remanescentes florestais. Brasília, PROBIO

Cervi, A.C., Paciornik, E.F., Vieira, R.F. \& Marques, L.C. 1989. Espécies vegetais de um remanescente de floresta de araucária (Curitiba, Brasil): Estudo preliminar I. Acta Biologia Paranaense 18(1-4): 73-114.

Dias, M.C.; Vieira, A.O.S.; Nakajima, J.N.; Pimenta, J.A. \& Lobo, P.C. 1998. Composição florística e fitossociologia do componente arbóreo das florestas ciliares do rio Iapó, na bacia do rio Tibagi, PR. Revista Brasileira de Botânica 21(2): 183-195.

Dias, M.C.; Vieira, A.O.S. \& Paiva, M.R. 2002. Florística e fitossociologia das espécies arbóreas das florestas da bacia do rio Tibagi. Pp. 109-124. In: Medri, M.E.; Bianchini, E.; Shibatta, O.A. \& Pimenta, J.A. (Eds.). A Bacia do Rio Tibagi. Londrina, UEL.

Dombrowski, L.T.D. \& Kuniyoski, Y.S. 1967. A vegetação do Capão da Imbuia. Araucariana 1: 1-18.

Galvão, F.; Kuniyoshi, Y.S. \& Roderjan, C.V. 1989. Levantamento fitossociológico das principais associações arbóreas da Floresta Nacional de Irati- PR. Revista Floresta 19: 30-49.

Jarenkow, J.A.; Baptista, L.R. De \& Moura, A. 1987. Composição florística e estrutura da mata com araucária na Estação Ecológica de Aracuri, Esmeralda, Rio Grande do Sul. Napaea 3: 9-18.

Koehler, A.; Netto, S.P. \& Sanquetta, C.R. 1998. Análise da estrutura de uma Floresta Ombrófila Mista semidevastada, Fazenda Gralha Azul, região metropolitana de Curitiba, com implicação ao manejo. Revista Acadêmica 1: 37-60.

Klein, R.M. 1960. O aspecto dinâmico do pinheiro brasileiro. Sellowia 12: 17-44.

Klein, R.M. \& Hatschbach, G. 1970/71. Fitofisionomia e notas complementares sobre o mapa fitogeográfico de Quero-Quero (Paraná). Boletim Paranaense de Geociências 28-29: 159-188.

Maack, R. 1968. Geografia física do Estado do Paraná. BADEP/UPFR/ IBTP, Curitiba.

Maack, R. 1981. Geografia física do Estado do Paraná. Livraria José Olympio, Rio de Janeiro.

Mccune, B. \& Mefford, M. J. 1999. PC-Ord version 4.4, multivariate analysis of ecological data. Users guide. Glaneden Beach, MjM Software Desing.

Melo, M.S. 2000. Canyon Guartelá. In: Schobbenhaus, C.; Campos, D.A.; Queiroz, E.T.; Winge, M. \& Berbert-Born, M. (Eds.) Sítios geológicos e paleontológicos do Brasil. Disponível em http://www.unb.br/ig/ sigeb/sitio094/sitio094.htm. (Acesso em 28/03/2010)

Moro, R.S.; Rocha, C.H.; Takeda, I.J.M. \& Kaczmarech, R. 1996. Análise da vegetação nativa da Bacia do Rio São Jorge. Publicatio 2(1): 33-56.

Moro, R.S.; Schmitt, J. \& Diedrichs, L.A. 2001. Estrutura de um fragmento da mata ciliar do Rio Cará-Cará, Ponta Grossa, PR. Publicatio 7(1): 19-38.
Mueller-Dombois, D. \& Ellenberg, H. 1974. Aims and methodos of vegetation ecology. Wiley and Sons, New York.

Nakajima, J.N.; Soares-Silva, L.H. \& Medri, M.E. 1996. Composição florística e fitossociológica do componente arbóreo das florestas ripárias da bacia do Rio Tibagi. 5. Fazenda Monte Alegre, município de Telêmaco Borba, Paraná. Arquivos de Biologia e Tecnologia 39(4): 933-948.

Nascimento, A.T., Longhi, S.J. \& Brena, D.A. 2001. Estrutura e padrões de distribuição espacial de espécies arbóreas em uma amostra de Floresta Ombrófila Mista em Nova Prata, RS. Ciência Florestal 11(1): 105-119.

Oliveira, Y.M.M. \& Rotta, E. 1982. Levantamento da estrutura horizontal de uma mata de araucária do primeiro planalto paranaense. Boletim de Pesquisa Florestal 4: 1-45.

Oliveira-Filho, A.T.; Carvalho, D.A.; Fontes, M.A.L.; Van Der Berg, E.; Curi, N. \& Carvalho, W.A.C. 2004. Variações estruturais do compartimento arbóreo de uma floresta semidecídua alto-montana na chapada das Perdizes, Carrancas, MG. Revista Brasileira de Botânica 27(2): 291-309.

Reitz, R. \& Klein, R.M. 1966. Flora Ilustrada Catarinense. Araucariáceas. Itajaí: Herbário Barbosa Rodrigues.

Rocha, C.H. \& Weirich Neto, P.H. 2007. Origem dos sistemas de produção e fragmentação da paisagem nos Campos Gerais. Pp. 171-179. In: Melo, M.S.; Moro, R.S. \& Guimarães, G.B. (Eds.).Patrimônio Natural dos Campos Gerais do Paraná. Ponta Grossa, Ed. UEPG.

Rondon Neto, R.M.; Watzlawick, L.F.; Caldeira, M.V.W. \& Schoeninger, E.R. 2002. Análise florística e estrutural de um fragmento de Floresta Ombrófila Mista Montana, situado em Criúva, RS, Brasil. Ciência Florestal 12(1): 29-37.

Sanquetta, C.R. \& Corte, S.D. 1998. Composição florística, estrutura e dinâmica de um fragmento florestal com Araucaria angustifolia no sudoeste paranaense. Revista Acadêmica 1: 3-28.

Shepherd, G.J. 1995. Fitopac: Manual do Usuário. Campinas, UNICAMP

Silva, F.C.; Fonseca, E.P.; Soares-Silva, L.H.; Muller, C. \& Bianchini, E 1995. Composição florística e fitossociologia do componete arbóreo das florestas ciliares da Bacia do Rio Tibagi: 3. Fazenda Bom Sucesso, Município de Sapopema, PR. Acta Botânica Brasílica 9(2): 289-301.

Silva, F.C. \& Marconi, L.P. 1990. Fitossociologia de uma floresta com araucária em Colombo, PR. Boletim de Pesquisas Florestais 20: 23-38.

Silva, F. Das C. \& Soares-Silva, L.H. 2000. Arboreal flora of the Godoy Forest state park, Londrina, PR. Brazil. Edinburg Journal of Botany 57(1): 107-120.

Silva, S.M.; Britez, R.M.; Souza, W.S., \& Motta, J.T.W. 1997. Levantamento florístico em área de várzea do rio Iguaçu, São Mateus do Sul, PR, Brasil. Arquivos de Biologia e Tecnologia 40(4): 903-913.

Silva, S.M.; Silva, F.C.; Vieira, A.O.S.; Nakajima, J.; Pimenta, J.A. \& Colli, S. 1992. Composição florística e fitossociologia do componente arbóreo das florestas ciliares da Bacia do Rio Tibagi. 2. Várzea do Bitumirim, Ipiranga, PR. Pp. 192-205. In: Anais do 2 Congresso Nacional sobre Essências Nativas. Instituto Florestal, São Paulo.

Soares-Silva, L.H. \& Barroso, G.M. 1992. Fitossociologia do estrato arbóreo da floresta na porção norte do Parque Estadual Mata dos Godoy, Londrina-PR, Brasil. Pp. 101-112. In: $8^{\circ}$ Congresso da SBSP. Campinas.

Soares-Silva, L.H.; Bianchini, E.; Fonseca, E.P.; Dias, M.C.; Medri, M.E. \& Zangaro Filho, W. 1992. Composição florística e fitossociologia do componente arbóreo das florestas ciliares da Bacia do Rio Tibagi. 1. Fazenda Doralice-Ibiporã, PR. Pp. 199-206. In: 2 Congresso Nacional sobre Essências Nativas. Anais. São Paulo: Instituto Florestal.

Soares-Silva, L.H., Kita, K.K. \& Silva, F.C. 1998. Fitossociologia de um trecho de floresta de galeria no Parque Estadual Mata do Godoy, Londrina, Pr, Brasil. Boletim do Herbário Ezechias Paulo Heringer 3: 46-62.

Takeda, I.J.M.; Moro, R.S.; Kaczmarech, R.; Bahls, L.M.C.; Bourguignon, M.V. \& Schardosin, E. 1998. Levantamento florístico do Parque Municipal Boca da Ronda, Ponta Grossa, PR. Publicatio 4(1): 49-63.

Veloso, H.P., Rangel Filho, A.L.R. \& Lima, J.C.A. 1991. Classificação da vegetação brasileira, adaptada a um sistema universal. IBGE DERMA, Rio de Janeiro.

Zar, J.H. 1996. Bioestatistical analysis. Prentice-Hall, New Jersey. 